\title{
ReGAE I2: preventing glaucoma blindness in the Caribbean through implementation of the Moorfields Safer Surgery System and skills transfer from the UK to Trinidad and Tobago
}

This article was published in the following Dove Press journal: Clinical Ophthalmology

\section{Desirée Murray, ${ }^{1,2}$ Peter Shah ${ }^{2-5}$ \\ 'Department of Clinical Surgical Sciences, The University of the West Indies, St Augustine, Trinidad and Tobago, West Indies; ${ }^{2}$ Birmingham Institute for Glaucoma Research, Institute of Translational Medicine, Birmingham, UK; ${ }^{3}$ University Hospitals Birmingham NHS Foundation Trust, Birmingham, UK; ${ }^{4}$ University College London, London, UK; ${ }^{5}$ Centre for Health \& Social Care Improvement, School of Health \& Wellbeing, University of Wolverhampton, Wolverhampton, UK}

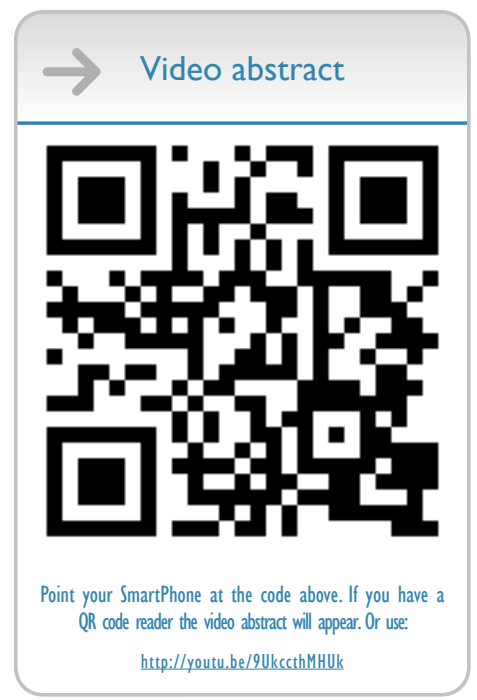

Correspondence: Desirée Murray Department of Clinical Surgical Sciences, The University of the West Indies, Building 68 2nd Floor, Eric Williams Medical Sciences Complex, Mount Hope, Trinidad and Tobago, West Indies

Tel/fax + I 8686634319

Email desiree.murray@sta.uwi.edu
Objective: The objective of the study was to present evidence of successful skills transfer of the Moorfields Safer Surgery System (MSSS) from the UK to Trinidad and Tobago and the safety and efficacy of this technique.

Methods: Hospital-based retrospective, consecutive, non-comparative case series study of 33 eyes (24 African-Caribbean patients; 16 male patients) with primary open-angle glaucoma undergoing trabeculectomy + mitomycin C (MSSS) by a single surgeon with UK Glaucoma Fellowship training. The clinical outcome measures included intraocular pressure (IOP), bleb morphology, postsurgical interventions, postoperative complications, and best-corrected visual acuity (BCVA) at the final follow-up.

Results: All patients were self-identified as African-Caribbean. The median age was 56 years (range 34-79 years). The mean preoperative IOP on maximum tolerated medical treatment was $22.4 \mathrm{mmHg}(\mathrm{SD}=5.9 \mathrm{mmHg})$. With or without medication, IOP was $\leq 21 \mathrm{mmHg}$ in $92.6 \%$ at 1 year and $87.5 \%$ at 5 years. At 1 year, IOP was $\leq 18 \mathrm{mmHg}$ in $78 \%, \leq 15 \mathrm{mmHg}$ in $73 \%$ and $\leq 14 \mathrm{mmHg}$ in $52 \%$. Removal of scleral flap releasable suture(s) was performed in $84 \%$, 5 -fluorouracil injection(s) in $88 \%$ and bleb needling revision in $38 \%$. The most common complication was early transient bleb leak (52\%). No patient developed endophthalmitis, hypotony maculopathy, suprachoroidal hemorrhage, or malignant glaucoma. At the final follow-up, 91\% had excellent or satisfactory bleb morphology, and $73 \%$ had equal or better BCVA.

Conclusion: Skills transfer between different geographical and economic regions contributes to the prevention of avoidable blindness through disease control - one of the core strategies of the World Health Organization's Vision 2020 initiative. In the Caribbean (Trinidad and Tobago), the MSSS was utilized by a surgeon with Glaucoma Fellowship training and achieved outcomes similar to best-published data. This success can be reproduced in other geographic locations. Keywords: glaucoma, trabeculectomy, mitomycin C, Caribbean, African Caribbean

\section{Introduction}

Glaucoma, cataract and diabetic retinopathy are the leading causes of blindness in the Caribbean. In Barbados, open-angle glaucoma (OAG) (28.4\%), cataract (27.7\%), or $\mathrm{OAG}$ and cataract combined (4\%) were responsible for $\sim 60 \%$ of blindness (bestcorrected visual acuity [BCVA] less than 3/60) in bilaterally blind persons. ${ }^{1}$ These diseases are all targeted in Vision 2020 - The Right to Sight initiative, a joint program of the World Health Organization and the International Agency for the Prevention of Blindness, which was launched in 1999. 2,3 The most recent action plan "Universal 
Eye Health: A Global Action Plan 2014-2019” (GAP) aims to reduce the prevalence of avoidable visual impairment by $25 \%$ by 2019 (compared to the baseline prevalence of 2010 ). ${ }^{4}$ All Commonwealth governments have committed to taking steps to accelerate universal health coverage (UHC); that is, making progress towards "ensuring that all people can use the promotive, preventive, curative, rehabilitative and palliative health services they need, of sufficient quality to be effective, while also ensuring that the use of these services does not expose the user to financial hardship" - World Health Organization. ${ }^{5}$ UHC is especially relevant to glaucoma, a leading cause of blindness in the Caribbean.

Glaucoma is a group of diseases characterized by selective death of retinal ganglion cells by apoptosis, with pathological optic nerve head changes and corresponding visual field loss. ${ }^{6}$ It accounts for the largest percentage of blindness in people aged 40-84 years in Barbados (28.4\%) and those aged 40 years and older in Trinidad and Tobago (32\%). ${ }^{1,7}$ In Suriname, it is the second most common cause of blindness in people aged 50 years and older $(23.8 \%)$ and the most common cause of blindness in Surinamese men (41.4\%). ${ }^{8}$ At one tertiary eye care institution in Trinidad and Tobago, $13 \%$ of patients diagnosed with glaucoma were bilaterally blind at initial presentation, $28 \%$ of glaucoma patients missed clinic appointments, and $40 \%$ were non-adherent to eye drops due to an unreliable supply and/or inability to afford medication (unpublished data from MSc dissertation, Murray D, London School of Hygiene and Tropical Medicine). One UK study has reported that late presentation of glaucoma is linked to higher risk of visual impairment in a patient's lifetime. ${ }^{9}$ The combination of advanced disease at presentation, high nonattendance rate, and non-adherence to medication create the perfect storm and partly explain the high prevalence of glaucoma blindness in the Caribbean region. In St Lucia, as per the Advanced Glaucoma Intervention Study (AGIS) criteria, the cumulative probability of reaching end-stage glaucoma, in at least one eye, among those with untreated eyes with glaucoma or suspected glaucoma, over a 10 -year period, was approximately 16\%. ${ }^{10,11}$ Findings from the Early Manifest Glaucoma Trial (EMGT) showed that lowering intraocular pressure (IOP) had positive effects in patients with manifest glaucoma, irrespective of initial IOP. ${ }^{12}$ Although both medical and surgical management of glaucoma are known to be beneficial, ${ }^{13,14}$ the glaucoma surgical rate (GSR) in the Caribbean and Latin America region remains low. Historical fear of complications and variable success rates following trabeculectomy + mitomycin C (MMC) in the Caribbean have deterred local ophthalmologists and patients from choosing filtration surgery as a treatment option. One factor contributing to this is the lack of research publication reporting surgical outcomes in the region, with only two peer-reviewed publications, one each from 1987 and 1998, to date. ${ }^{15,16}$

Ten-year data from the Collaborative Initial Glaucoma Treatment Study (CIGTS), using all available follow-up through 9 years after treatment initiation, showed that initial surgery was beneficial for subjects with more advanced visual field loss at presentation. ${ }^{13}$ This landmark publication highlights the importance of surgical intervention as an option for lowering IOP to prevent glaucoma blindness. Publication of clinical data and surgical outcomes based on real-world experiences in the Caribbean would provide evidence that modern-day glaucoma filtration procedures such as trabeculectomy + MMC using the Moorfields Safer Surgery System (MSSS) can be safely and successfully implemented in lower resource settings. Only then will the key stakeholders including government, service providers, and our patients begin to reassess all available options to prevent avoidable glaucoma blindness in the Caribbean and elsewhere.

The three core Vision 2020 strategies to be implemented by national programs are 1) disease control: facilitate the implementation of specific programs to control and treat the major causes of blindness; 2) human resource development: support training of ophthalmologists and other eye care personnel to provide eye care; and 3) infrastructure and appropriate technology development: assist to improve infrastructure and technology to make eye care more available and accessible. ${ }^{17}$

At the University of the West Indies (UWI), the human resource development component of Vision 2020 aligns perfectly with the institution's primary mandate to serve in the advancement of the Caribbean community and sustain its development. Academic staff have pursued the MSc in Public Health for Eye Care, postgraduate training in ophthalmology, and undergraduate training in optometry have been introduced, and training of graders for diabetic retinopathy photographic screening has commenced. Consideration is also being given to the introduction of a postgraduate degree in ophthalmic nursing specialization. The MAPS Mission (Mainstreaming, Acceleration and Policy Support) aims to incorporate the United Nations Sustainable Development Goals into Trinidad and Tobago's National Development Strategy 2016-2030 (Vision 2030). This includes good health and well-being (Goal \#3) and partnerships for the goals (Goal \#17). ${ }^{18}$ Globally, all cadres of eye care professionals advocate and support increased surgical intervention in our populations. In the UK, the MSSS trabeculectomy technique 
has been shown to be safe and effective and improved surgical outcomes in African-Caribbean patients with primary open-angle glaucoma (POAG). ${ }^{19,20}$ This work formed part of the ReGAE (Research into Glaucoma And Ethnicity) project based in Birmingham, UK. ${ }^{21}$ Our study aimed to provide evidence that the ReGAE findings can be translated across different geographical and economic regions to prevent avoidable glaucoma blindness outside the UK.

In addition to increasing the odds of preserving visual field by minimizing issues related to poor adherence to medical treatment, traditional glaucoma filtration surgery eliminates IOP fluctuation and achieves long-term stable low IOPs. However, the advent of the minimally invasive glaucoma surgery (MIGS) era has further reduced the likelihood of traditional glaucoma filtration surgery being considered. This can have negative consequences for patients with advanced disease and/or normal tension glaucoma who require low pressures not consistently achievable with MIGS. Trabeculectomy with adjunctive use of antifibrotic agents remains the best option to preserve visual function in these patients. ${ }^{13,22}$ Trabeculectomy is the only surgical procedure in which both intra- and postoperative titration of IOP, through suture manipulation and bleb management, are possible. Publication of real-world evidence-based outcomes is essential to form opinions and influence clinical and administrative decision-making.

\section{Methods}

This is a retrospective, non-comparative, longitudinal case series study of 33 consecutive eyes undergoing trabeculectomy + MMC. All procedures were performed by a single surgeon (DM). The study was performed and assessed using the World Glaucoma Association (WGA) Guidelines on design and reporting of glaucoma surgical trials. ${ }^{23}$ However, in this realworld, resource-limited setting, the principal surgeon(DM) was also the principal investigator and was directly involved in both clinical care and data collection. Clinical data for analysis was obtained during routine pre- and postoperative clinic visits. Due to the constraints of local glaucoma care, such as lack of equipment and adequately trained staff, preoperative and one-year postoperative visual field mean deviations, as recommended by the WGA, were not reported.

The series included 24 patients (16 male patients) with POAG, who self-identified as African-Caribbean. The diagnosis of POAG was based on the characteristic optic disc and/or visual field changes and open drainage angle on gonioscopy. Elevated IOP $>21 \mathrm{mmHg}$ was not required for diagnosis, although IOP level was used as a measure of therapeutic success.
Surgery was performed by a UK-fellowship-trained surgeon using the MSSS technique. Patients needing surgery on both eyes had each eye analyzed as a separate case record. The data were also disaggregated to allow independent analysis of first eye surgery. Previous cataract and/or glaucoma surgeries were not exclusion criteria. Postoperative data were collected during routine clinical care at 3,6, and 12 months and then annually up to the final clinic visit. Clinical outcome measures included IOP reduction, bleb morphology, postsurgical interventions, operative complications, and BCVA at the final follow-up. Median follow-up was 48.5 months (range 7-107 months). Surgical failure was defined as IOP $>21 \mathrm{mmHg}$ with or without treatment, or the need to undergo further glaucoma surgery (except removal of scleral flap releasable sutures and bleb needling revision) for raised IOP. In the absence of hypotony maculopathy, IOP $<6 \mathrm{mmHg}$ was not considered a failure. The clinical outcomes were compared to published data from a similar demographic cohort in the UK. ${ }^{20}$ A Kaplan-Meier survival analysis curve of data was produced.

\section{Statement of ethics}

Ethical approval was granted by the Campus Ethics Committee of the UWI, St Augustine. All applicable institutional and governmental regulations concerning the ethical use of human volunteers were followed during this research. As a result of loss to follow-up ( $79 \%$ after 5 years), due to transfer of care, emigration, and death, all participants in this research could not provide written informed consent for this retrospective study. All study participants were de-identified.

\section{Surgical technique}

Surgery was performed under general or local (sub-Tenon's preservative-free bupivacaine $0.5 \%$ ) anesthesia. A 7/0 black silk or 6/0 vicryl corneal traction suture was placed superiorly using a reverse-cutting spatulated needle. A fornix-based conjunctival flap was created, and a large sub-Tenon's pocket was made in the superior fornix by dissecting posteriorly using curved Westcott spring scissors. Hemostasis was achieved with minimal cautery to scleral vessels, and residual episcleral tissue was removed with a No 15 stainless steel blade. All patients received $0.2 \mathrm{mg} / \mathrm{mL}$ MMC (reconstituted with water for injection) for 3-5 minutes. A specially designed atraumatic conjunctival clamp was used to grasp the free edge of the conjunctiva at the limbus to minimize contact with MMC. Lint-free/fiber-free/cellulose-free polyvinyl acetate eye spears pre-soaked with MMC were placed in the sub-Tenon's pocket to treat a wide surface area of the future 
bleb. The sub-Tenon's space and ocular surface were then irrigated with $30-40 \mathrm{~mL}$ of balanced salt solution. A partial thickness rectangular scleral flap of $4 \mathrm{~mm}$ wide $\times 3 \mathrm{~mm}$ long was fashioned. Pre-placed buried 10/0 nylon releasable scleral flap sutures were placed at the posterior corners of the scleral flap. An oblique paracentesis was made using a $20-\mathrm{G}$ microvitreoretinal blade. The anterior chamber was entered under the scleral flap through the peripheral cornea using a 30-degree blade. A full-thickness sclerostomy made with a Khaw Descemet's punch and a small peripheral iridectomy were performed. The 10/0 nylon scleral flap sutures were then tied tightly, using a three-throw releasable knot, ensuring minimal drainage at the posterior lip of the scleral flap. The anterior chamber was reformed with balanced salt solution, and the paracentesis was made water tight by corneal stromal hydration. Conjunctiva and Tenon's capsule were closed with two 10/0 nylon purse-string sutures at the peripheral edges and two central mattress sutures. Sub-Tenon's gentamicin $(0.25 \mathrm{~mL}-10 \mathrm{mg})$ and dexamethasone $(0.25 \mathrm{~mL}-1 \mathrm{mg})$ were administered and an eye pad and shield applied.

\section{Postoperative management}

All eyes were examined on the first postoperative day, thereafter, weekly for the first month and then as needed. Patients were prescribed prednisolone acetate $1 \%$ eye drops between 4 times daily and every 2 hours, and ofloxacin $0.3 \%$ or moxifloxacin $0.5 \%$ topical antibiotics. Aqueous flow was titrated with the healing response (based on bleb vascularity and inflammation) by performing bleb massage, scleral flap releasable suture removal, and subconjunctival 5-fluorouracil (5-FU) (5 mg) as needed. To rescue a failing bleb, needling revision (sub-Tenon's \pm sub-scleral flap) with subconjunctival injections of 5-FU (5 mg) and dexamethasone (1 mg) was performed under sterile conditions in the operating theater.

\section{Results}

Thirty-three eyes (23 first eyes and 10 second eyes) of 24 patients underwent trabeculectomy + MMC. Case note retrieval was $100 \%$. Median age at surgery was 54 years (range 34-77 years) for first eye procedures and 56 years (range 34-79 years) for all procedures. Twenty-one percent of cases had BCVA of $<3 / 60$ in at least one eye at surgical intervention. Data were available for analysis on 27 eyes (82\%) at 1-year and on 24 eyes $(73 \%)$ at 2 -year follow-up.

The mean presenting IOP was $28.5 \pm 10.4 \mathrm{mmHg}$ (range 11-64 $\mathrm{mmHg}$ ), and preoperative IOP on maximum tolerated medical treatment (MTMT) was $22.9 \pm 7.6 \mathrm{mmHg}$ (range $10-50 \mathrm{mmHg}$ ). At 1 year, with or without medication, IOP was $\leq 18 \mathrm{mmHg}$ in $78 \%, \leq 15 \mathrm{mmHg}$ in $63 \%$ and $\leq 14 \mathrm{mmHg}$ in $52 \%$ (Figure 1). Mean IOP was $15.7 \pm 7.6 \mathrm{mmHg}, 15 \pm 4 \mathrm{mmHg}, 16 \pm 5 \mathrm{mmHg}, 16 \pm 5 \mathrm{mmHg}$, and $14 \pm 5.5 \mathrm{mmHg}$ at $1,2,3,4$, and 5 years, respectively, postoperatively (Figure 2). For first eyes, mean presenting IOP was $29.5 \pm 11.6 \mathrm{mmHg}$ (range 11-64 $\mathrm{mmHg}$ ) and preoperative IOP on MTMT was $23.2 \pm 8.6 \mathrm{mmHg}$ (range $13-50 \mathrm{mmHg}$ ). Mean IOP was $15.4 \pm 8.8 \mathrm{mmHg}, 15.0 \pm 5.0 \mathrm{mmHg}, 14.8 \pm 5.5$ $\mathrm{mmHg}, 15.5 \pm 5.8 \mathrm{mmHg}$ and $13.7 \pm 5.6 \mathrm{mmHg}$ at $1,2,3,4$ and 5 years postoperatively (Figure 3 ).

IOP was $\leq 21 \mathrm{mmHg}$ in $92.6 \%$ of patients at 1 year and in $87.5 \%$ at 5 years. Kaplan-Meier cumulative survival curve for success, with 95\% confidence intervals, is shown in Figure 4.

Table 1 provides details of significant postoperative events compared to similar trials in the UK. Removal of scleral flap releasable suture(s) was required in $84 \%, 5$-FU injection(s) in

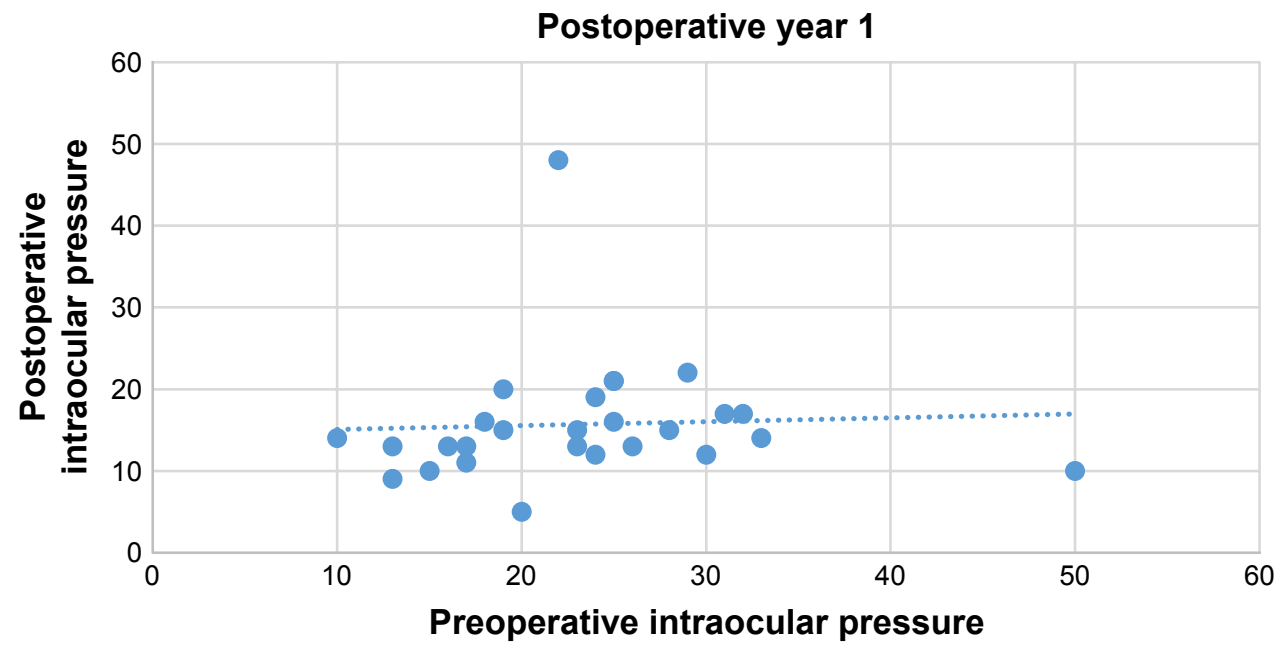

Figure I Scatter plot showing intraocular pressure (IOP) at postoperative year I relative to preoperative IOP, with trend line. At postoperative year I, the majority of patients had IOP $\leq 14 \mathrm{mmHg}$, range $9-22 \mathrm{mmHg}$ with outliers at 48 and $5 \mathrm{mmHg}$.

Notes: IOP $\leq 21 \mathrm{mmHg} 25 / 27$ eyes (93\%); IOP $\leq 18 \mathrm{mmHg} 2 \mathrm{I} / 27$ eyes (78\%); IOP $\leq 15 \mathrm{mmHg}$ I7/27 eyes (63\%); IOP $\leq$ I4 mmHg I4/27 eyes (52\%). 


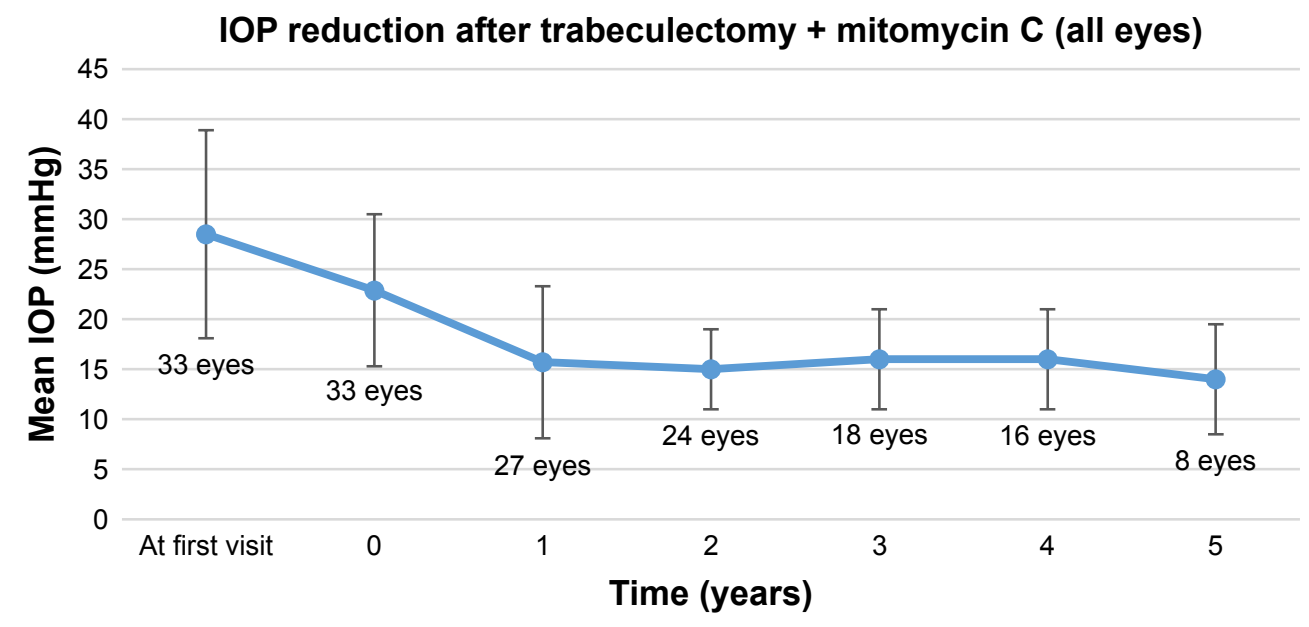

Figure 2 Post-trabeculectomy mean intraocular pressure (IOP) reduction \pm standard deviation (all eyes).

Note: Time 0 refers to time of surgery.

$88 \%$, and bleb needling revision in $38 \%$. The most common complication was early bleb leak (52\%). No patient developed endophthalmitis, suprachoroidal hemorrhage, hypotony maculopathy, or malignant glaucoma. At final follow-up, $91 \%$ had excellent or satisfactory bleb morphology, and $73 \%$ had equal or better BCVA in the operated eye.

\section{Discussion}

Glaucoma is a leading cause of blindness in the Caribbean. The prevalence of $\mathrm{OAG}$ in the population ranges from $7 \%$ in the black population of 40-84 years of age in Barbados to $8.8 \%$ in the 30 years and older population in St Lucia. ${ }^{25,26}$ In Barbados, the 9-year incidence of definite OAG was $4.4 \%$ (95\% CI, 3.7\%-5.2\%), and OAG (21\%) was the second most common cause of incidental bilateral blindness $(<6 / 120)$ in the Barbados Eye Studies, after cataract (43\%). ${ }^{27,28}$ In England, Humphrey visual field mean deviation of the worse eye, at the first hospital visit, was used as an estimate of vision loss for a patient at diagnosis. Although severity of vision loss at the point of glaucoma detection improved over a 13-year period, the authors noted that a large number of patients still presented at glaucoma clinics with significant vision loss in at least one eye. ${ }^{29}$

Ten-year data from the CIGTS, using all available follow-up through 9 years after treatment initiation, showed that initial surgery was beneficial for subjects with more advanced visual field loss at presentation. ${ }^{13} \mathrm{~A}$ strong case can be made for advocating for surgical treatment in the Caribbean. African ancestry, high prevalence of glaucoma, younger age at diagnosis, late presentation with advanced disease, and high rates of glaucoma blindness highlight the need for low target IOPs to preserve vision. Logistical and economic factors associated with medical management of glaucoma (including high levels

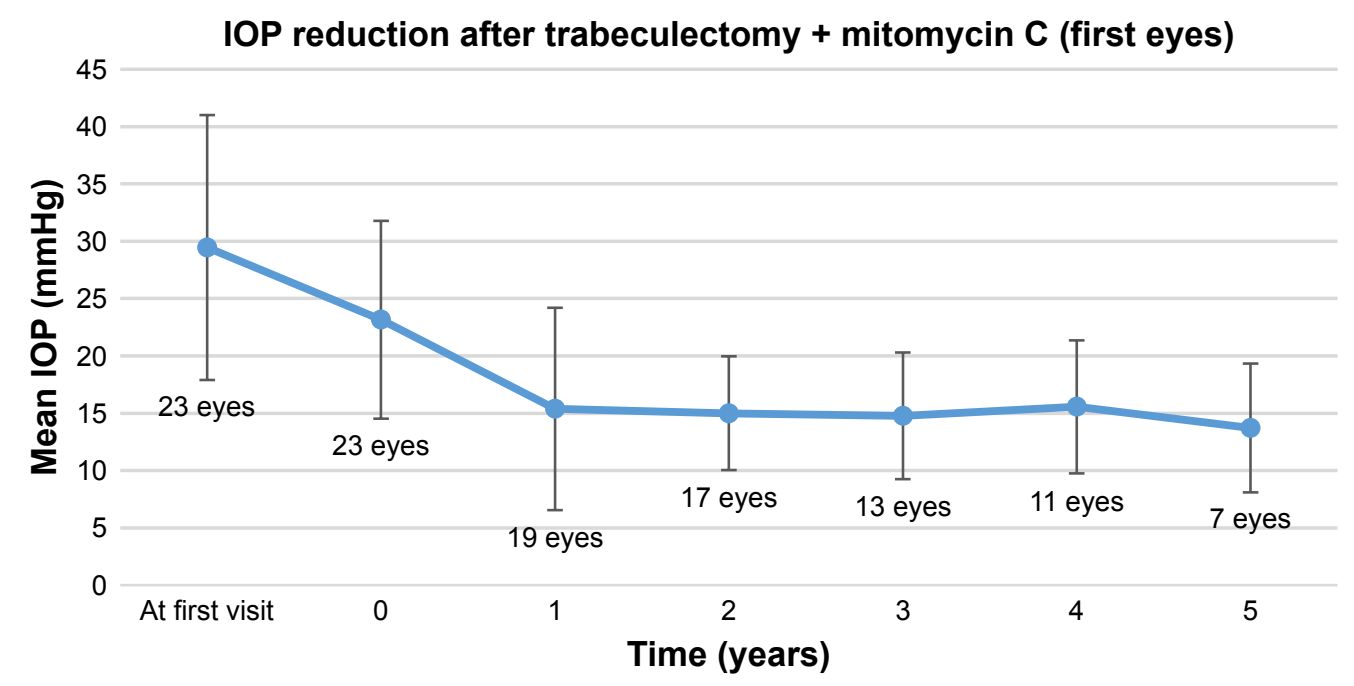

Figure 3 Post-trabeculectomy mean intraocular pressure (IOP) reduction \pm standard deviation (first eyes).

Note: Time 0 refers to time of surgery. 


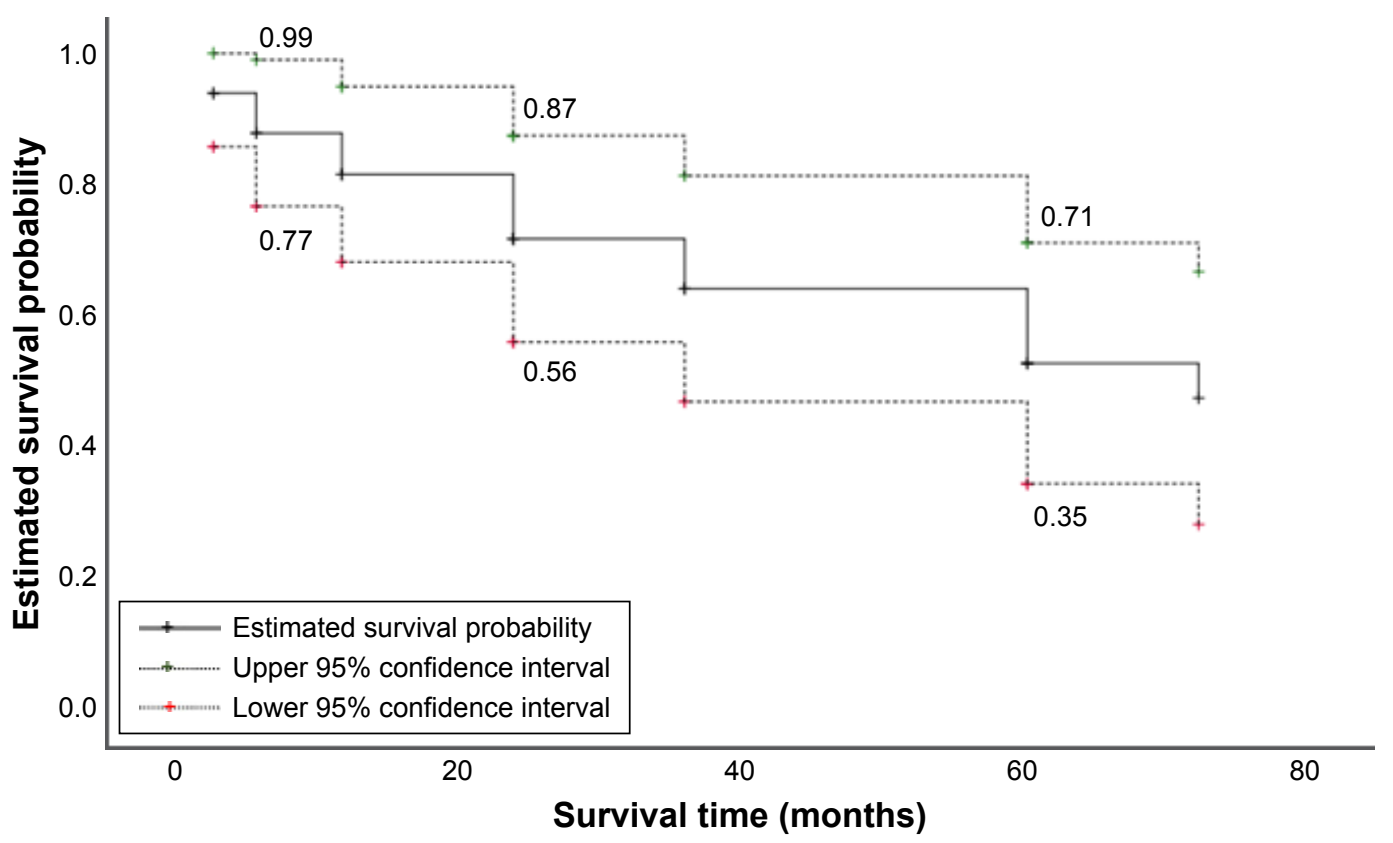

Figure 4 Kaplan-Meier cumulative survival probability curve for success with or without the use of intraocular pressure (IOP), lowering medication, after trabeculectomy + mitomycin C (MMC).

Notes: The cumulative survival probability of IOP $\leq 2 \mathrm{I} \mathrm{mmHg}$ with or without IOP lowering medication at any time after baseline. Reference for the $95 \%$ confidence interval (Cl): applied analysis survival by Hosmer, Lemeshow, and May.

of poverty and deprivation) also favor surgical intervention as an option for lowering IOP. MIGS combined with cataract surgery or as a stand-alone procedure has become increasingly popular, but trabeculectomy remains the operation of choice in patients with advanced disease and uncontrolled IOP despite MTMT. Previous studies have demonstrated that multiple risk factors for treatment failure and glaucoma progression aggregate to contribute to the high rates of glaucoma blindness. ${ }^{30-35}$ The MSSS was introduced into a Caribbean setting to improve surgical outcomes and help prevent avoidable glaucoma blindness associated with the following risk factors.

Table I Significant postoperative events

\begin{tabular}{llll}
\hline $\begin{array}{l}\text { Significant } \\
\text { postoperative events }\end{array}$ & $\begin{array}{l}\text { UK* } \\
\text { (\%) }\end{array}$ & $\begin{array}{l}\text { UK } \\
\text { (\%) }\end{array}$ & $\begin{array}{l}\text { Trinidad and } \\
\text { Tobago (\%) }\end{array}$ \\
\hline $\begin{array}{l}\text { Adjustment or release of } \\
\text { scleral flap sutures }\end{array}$ & $63.8^{8}$ & Not specified & 84 \\
$\begin{array}{l}\text { Subconjunctival } \\
\text { 5-fluorouracil }\end{array}$ & 46.8 & 27 & 88 \\
Bleb leak & $8.5^{\pi}$ & 0.8 & $52^{*}$ \\
Bleb needling revision & 21.3 & 14 & 38 \\
Endophthalmitis & 0 & 0 & 0 \\
Suprachoroidal hemorrhage & 0 & 0 & 0 \\
Hypotony maculopathy & 0 & 0 & 0 \\
Malignant glaucoma & 0 & Not specified & 0 \\
\hline
\end{tabular}

Notes: *ReGAE 7: long-term outcomes of augmented trabeculectomy with mitomycin $C$ in African-Caribbean patients. ${ }^{20}$ jayaram et al. ${ }^{24}$ sWithin 3 months. "Significant early hypotony with bleb leak. ${ }^{*}$ Bleb leak defined as a positive Seidel test at any stage, performed using a fluorescein strip.

Abbreviation: ReGAE, Research into Glaucoma And Ethnicity.

\section{African ancestry and large burden of disease}

The long-term risk of OAG in African-descent populations is higher than that in communities of European ancestry. In Barbados, the prevalence of OAG in the black population was eight times more than that of other ethnic groups. ${ }^{25} \mathrm{In}$ Baltimore, USA, age-adjusted prevalence rates for POAG were four to five times higher in blacks as compared with whites. $^{31,35}$ A Bayesian meta-regression model concluded that after adjusting for age, gender, habitation type, response rate, and year of study, people of African ancestry were more likely to have POAG than people of European ancestry (odds ratio [OR], 2.80; 95\% CI, 1.83-4.06). ${ }^{36} \mathrm{~A}$ study conducted in an urban Canadian screening population reported that African-Caribbean ancestry was associated with increased risk factors for OAG development, including higher IOP $(p<0.001)$ and thinner central corneal thickness $(p<0.001) .{ }^{37}$ The African Descent and Glaucoma Evaluation Study (ADAGES) III Genomics Study Group reported similar findings: after adjusting for age, African descent POAG patients had different phenotypic characteristics compared with European descent POAG patients, including higher IOP and thinner corneas $(p<0.001){ }^{38}$

\section{Younger age at diagnosis}

POAG appears $\sim 10$ years earlier and progresses more rapidly in blacks than in whites. ${ }^{33}$ A study in England reported that at 
the time of diagnosis of glaucoma, median age of the 25,521 patients included in the analysis was 67 years (interquartile range 55-76 years)..$^{29}$ In our study, median age at surgery was 56 years (range 34-79 years). A study to determine the impact of African-Caribbean race on risk factors for glaucoma in an urban Canadian population reported that Caucasians were significantly older (66 [SD 12] years) than African Caribbeans (56 [SD 12] years) ( $p=0.001) .{ }^{37}$ The ADAGES III Genomics Study Group reported that the African descent POAG patients and control participants were significantly younger (both 67.4 years) than European descent POAG patients and control participants (73.4 and 70.2 years, respectively). ${ }^{38}$ In Sweden, out of the 423 predominantly Caucasian patients reported, median age at the time of OAG diagnosis was 74 years (range $46-95$ years). ${ }^{39,40}$

\section{High prevalence and incidence of "normal" tension glaucoma}

Normal tension glaucoma may represent up to $50 \%$ of all OAG in the Caribbean. In St Lucia, mean untreated IOP of 155 glaucoma and suspected glaucoma cases that followed up after 10 years was $21 \mathrm{mmHg}$ at baseline, suggesting that half of the patients with $\mathrm{OAG}$ and suspected glaucoma could have IOPs below $22 \mathrm{mmHg} .{ }^{26}$ In Barbados, as much as 48\% of incidents of OAG developing over 9 years occurred with IOP $<21 \mathrm{mmHg}$ at baseline. Of the new cases of OAG over a 9-year period, 53\% were undetected and one-third of these had IOP of $21 \mathrm{mmHg}$ or less. ${ }^{27}$ This is consistent with other studies of glaucoma in populations of African descent, such as the Baltimore Eye Survey, in which the average IOP among black patients with glaucoma who were receiving treatment was virtually identical to that in those black patients who were not receiving treatment (median IOP, $20 \mathrm{mmHg}$ ). More than half of all glaucomatous eyes had a screening IOP below $21 \mathrm{mmHg}$, whether these eyes were receiving treatment or not. ${ }^{41}$ The results of these studies highlight the importance of IOP phasing to assess diurnal IOP variation. They also emphasize the need for lower target IOPs in African-Caribbean patients with glaucoma, best achieved through surgical intervention.

\section{Advanced disease at a younger age}

In the Barbados Eye Studies, more than half (53\%) of new cases of OAG were undetected. ${ }^{27}$ Similarly, in East Baltimore, in an ethnically mixed US community, comparable proportions of blacks and whites (50\%) were aware they had the disease. However, blindness due to POAG began 10 years earlier among blacks compared to whites. POAG accounted for $13 \%$ of blindness in blacks younger than 65 years, but was not a cause of blindness among whites of the same age $(0 \%)$. Among blacks, the overall ageadjusted rate of glaucoma blindness in one or both eyes was 6.6 times more than that among whites. ${ }^{34}$ The ADAGES III Genomics Study Group reported that after adjusting for age, African descent POAG patients had worse visual acuity and visual field mean deviation than European descent patients $(p<0.001) .{ }^{38}$ In our study, median age at surgery on the first eye was 54 years, and $21 \%$ of all cases (first and/or second eyes) had BCVA $<3 / 60$ in at least one eye at the time of surgery. In contrast, a study of 423 Swedish patients reported that the median age when developing bilateral blindness was 86 years (range 66-98 years). ${ }^{40}$

\section{Multiple risk factors for progression and high rates of glaucoma blindness}

There has been much research and discussion regarding the risk factors for POAG progression, with genetics playing an important role. ${ }^{42}$ A 1982 retrospective survey from the Massachusetts Eye and Ear Infirmary reported that Boston blacks were four to five times more likely to be blind from POAG than whites and asked: "Why do some people go blind from glaucoma?" 31 They concluded that "the worse the initial condition of the eye, the lower the tension needs to be to prevent further loss or blindness." Much of this reasoning is still applicable and has been supported by more recent studies. A retrospective study of 3,790 UK patients in glaucoma clinics, using linear regression of visual field mean deviation over time, reported that more than $90 \%$ (CI $85.7 \%-94.3 \%$ ) of patients predicted to progress to statutory blindness had a mean deviation worse than $-6 \mathrm{~dB}$ in at least one eye at presentation. The researchers concluded that the likelihood of patients suffering visual impairment in their lifetime is linked to visual field loss at presentation with late presentation of glaucoma being associated with higher risk of visual impairment in a patient's lifetime. ${ }^{9}$ There is also now strong evidence that lower target IOPs are associated with better preservation of vision. ${ }^{43}$

\section{Medical versus surgical treatment}

Target IOP can be achieved by medical, surgical (including MIGS), or laser intervention. However, 10-year data from the CIGTS showed that initial surgery was beneficial for subjects with more advanced visual field loss at presentation. ${ }^{13}$ In 1996, while noting that patients often refuse a primary surgical procedure, Merritt advocated trabeculectomy rather than topical medications once the diagnosis of POAG had been confirmed by full-threshold perimetry. He argued that topical medications had not produced protective effects on the 
glaucomatous disease, that topical glaucoma agents adversely affected the conjunctiva, lowering the success rates of subsequent filtration procedures, and that laser therapies had not been effective in African Americans. ${ }^{32}$

Currently, randomized controlled trials using selective laser trabeculoplasty (SLT) on individuals of African descent in St Lucia are ongoing ${ }^{44}$ and show promising early results. In the United States, Osterman et al reported that ethnic differences in glaucoma care among Medicare beneficiaries may reflect greater severity of disease at diagnosis. ${ }^{45}$ Surgery rate among blacks was 0.15 compared to 0.08 among whites, with blacks being $88 \%$ more likely to have surgery for glaucoma during a year. After controlling for other factors, blacks were $78 \%$ more likely to undergo surgery.

\section{Low GSR}

GSR has been defined as the annual number of total glaucoma surgeries performed per million population. GSR is a proxy indicator for glaucoma care. Global rates of glaucoma surgery are lowest in those regions with the greatest burden of disease, ranging from 2.9 (Ivory Coast), 7.0 (Ghana, 2010), 30 (Sudan), 132.4 (UK, 2004), 274.3 (USA, 2006) to 500 (Germany) per million per year. ${ }^{46}$ In the Caribbean, although late presentation and an unreliable supply and/or inability to afford medication contribute to poor adherence and failure of medical treatment, which favor surgical intervention, the GSR is low. Historically, African-Caribbean patients have been at high risk for failure of trabeculectomy surgery. ${ }^{30}$ To achieve high longterm success rates, Glaucoma Fellowship training is needed as meticulous surgical technique and intensive postoperative management including removal or laser suture lysis of scleral flap releasable sutures, subconjunctival 5-FU injections, and bleb needling revision are required. The labor-intensive postoperative management reported in this case series is similar to reports from the UK, ${ }^{20,24}$ although bleb leak, bleb needling revision, and subconjunctival 5-FU were substantially higher than in the UK case series. The low rates of endophthalmitis, suprachoroidal hemorrhage, hypotony maculopathy, and malignant glaucoma were comparable (Table 1).

\section{Lessons learnt}

Although early, high aqueous flow through the developing filtration operation is important, the high rate of early transient bleb leak (52\%) in this study highlights the need for careful closure of the conjunctiva and Tenon's capsule. Subsequent modification of the MSSS technique has included more meticulous suturing of conjunctiva with overlap of buried mattress sutures along the edge of the peritomy. In addition, an increased concentration of MMC from 0.2 to $0.4 \mathrm{mg} / \mathrm{mL}$ is now applied under the scleral flap for 3 minutes in addition to the standard sub-Tenon's MMC treatment.

\section{Strengths}

This was a consecutive case series from a UK-Fellowshiptrained single surgeon (DM) in a developing real-world scenario. It is the first study to document the successful implementation of the MSSS in an indigenous African-Caribbean population, with high rates of success and low rates of surgical complications, demonstrating that Glaucoma Fellowship training makes successful skills transfer possible.

\section{Limitations Missing data Baseline IOP}

Clinical data for analysis were obtained during routine preand postoperative clinic visits, and single values were used for documenting IOP. Some patients had already commenced glaucoma treatment elsewhere, so true baseline IOP was not always available.

\section{Follow-up data}

Scheduling of appointments at 3 months, 6 months, 1 year, 2 years, 3 years, 4 years, and 5 years was variable. Some missed appointments were caused by provider factors such as hospital-initiated deferrals (appointments rescheduled or cancelled), administrative errors, or industrial action. In addition, patients often failed to attend for scheduled appointments due to many reasons, including scheduling conflicts, work commitments, forgetting, no escort to accompany them, or transportation issues. Therefore, because of sporadic attendance, data from the visit closest to this pre-scheduled follow-up time point was collected and analyzed, but the reporting time window was no greater than 30 days.

\section{Definition of success}

Evidence of glaucoma progression was not collected, and visual field mean deviation was not analyzed either pre- or postoperatively. Due to the constraints of local glaucoma care, preoperative and one-year postoperative visual field mean deviations, as recommended by the WGA, were not always available. Analysis of previous or subsequent cataract surgery and change in visual acuity was not conducted. Information on the percentage of patients who had cataract surgery following trabeculectomy + MMC could have explained why BCVA improved in some patients over time. Quality of life indicators were not evaluated. 


\section{Loss to follow-up}

Loss to follow-up due to non-attendance was high (79\% after 5 years), especially after second eye surgery. Causes included transfer between private and public care, change of address locally, emigration due to job opportunities, and death.

\section{Conclusion}

Glaucoma in the African-Caribbean population is an aggressive disease which often affects young adults. This study provides evidence that the MSSS can be implemented successfully in the Caribbean, achieving comparable outcomes to those obtained in similar populations in the UK. Advanced disease at presentation and non-adherence to medical treatments are strong factors for surgical intervention, although intensive bleb management and postoperative care are required for good surgical outcomes. Trabeculectomy with adjuvant anti-scarring MMC is the gold standard for external filtration procedures in many communities globally. This study adds to the evidence base that trabeculectomy + MMC can be safely implemented into populations at high risk of glaucoma blindness. Improving the evidence base for surgical intervention is the first step in gaining the trust of the populations we aim to help.

\section{Acknowledgments}

We thank Professor Graham Lee (Brisbane) and International Centre for Eye Health, London School for Hygiene and Tropical Medicine for providing the insight and expertise that greatly assisted the research. This study was previously presented as a poster at the Royal College of Ophthalmologists Annual Congress, Birmingham, UK, May 2016. The institution at which the work was carried out is The University of the West Indies, St Augustine, Trinidad and Tobago, West Indies.

\section{Disclosure}

The authors report no conflicts of interest in this work.

\section{References}

1. Hyman L, Wu SY, Connell AM, et al. Prevalence and causes of visual impairment in the Barbados eye study. Ophthalmology. 2001;108(10): 1751-1756.

2. Garms RC. The global initiative: launch of Vision 2020. Community Eye Health. 1998;11(28):56-57.

3. McGavin DD. The global initiative for the elimination of avoidable blindness - Vision 2020: the right to sight. Community Eye Health. 1999; 12(30):32.

4. IAPB [webpage on the Internet]. What is VISION 2020? Available from: https://www.iapb.org/global-initiatives/vision-2020/what-is-vision2020/. Accessed May 14, 2018.

5. Commonwealth Health Ministers Meeting 2017 [webpage on the Internet]. Available from: http://thecommonwealth.org/chmm2017\#sthash. x5hUXrkC.dpuf. Accessed May 14, 2018.
6. Quigley HA. Neuronal death in glaucoma. Prog Retin Eye Res. 1999; 18(1):39-57.

7. Braithwaite T, Bartholomew D, Deomansingh F, et al; for the NESTT Study Group. The National Eye Survey of Trinidad and Tobago: prevalence and causes of blindness and vision impairment. West Indian MedJ. 2015;64(Suppl 3):14.

8. Minderhoud J, Pawiroredjo JC, Themen HC, et al. Blindness and visual impairment in the Republic of Suriname. Ophthalmology. 2015; 122(10):2147-2149.

9. Saunders LJ, Russell RA, Kirwan JF, McNaught AI, Crabb DP. Examining visual field loss in patients in glaucoma clinics during their predicted remaining lifetime. Invest Ophthalmol Vis Sci. 2014;55(1):102-109.

10. Wilson MR, Kosoko O, Cowan CL Jr, et al. Progression of visual field loss in untreated glaucoma patients and glaucoma suspects in St. Lucia, West Indies. Am J Ophthalmol. 2002;134(3):399-405.

11. [No authors listed]. The advanced glaucoma intervention study (AGIS): 3. Baseline characteristics of black and white patients. Ophthalmology. 1998;105(7):1137-1145.

12. Heijl A, Leske MC, Bengtsson B, Hyman L, Bengtsson B, Hussein M; Early Manifest Glaucoma Trial Group. Reduction of intraocular pressure and glaucoma progression: results from the Early Manifest Glaucoma Trial. Arch Ophthalmol. 2002;120(10):1268-1279.

13. Musch DC, Gillespie BW, Lichter PR, Niziol LM, Janz NK. Visual field progression in the Collaborative Initial Glaucoma Treatment Study: the impact of treatment and other baseline factors. Ophthalmology. 2009;116(2):200.e1-207.e1.

14. Garway-Heath DF, Crabb DP, Bunce C, et al. Latanoprost for open-angle glaucoma (UKGTS): a randomised, multicentre, placebocontrolled trial. Lancet. 2015;385(9975):1295-1304.

15. Shingleton BJ, Distler JA, Baker BH. Filtration surgery in black patients: early results in a West Indian population. Ophthalmic Surg Lasers Imaging Retina. 1987;18(3):195-199.

16. Chen PP, Basich FM, Khadem E. Trabeculectomy with long-term-stored mitomycin C in a West Indian population. Ophthalmologica. 1998; 212(6):404-406.

17. WHO [webpage on the Internet]. Prevention of blindness and visual impairment. Available from: http://www.who.int/blindness/partnerships/vision2020/en/. Accessed May 14, 2018.

18. Sustainable development goals: 17 goals to transform our world [webpage on the Internet]. Available from: http://www.un.org/sustainabledevelopment/sustainable-development-goals/. Accessed May 14, 2018.

19. Kirwan JF, Lockwood AJ, Shah P, et al. Trabeculectomy in the 21 st century: a multicenter analysis. Ophthalmology. 2013;120(12):2532-2539.

20. Shah P, Agrawal P, Khaw PT, Shafi F, Sii F. ReGAE 7: long-term outcomes of augmented trabeculectomy with mitomycin $\mathrm{C}$ in African Caribbean patients. Clin Exp Ophthalmol. 2012;40(4):e176-e182.

21. Shah P, Cross V. ReGAE 1: using the Shah-Cross model as an orientating framework in African-Caribbean glaucoma research. Eye (Lond). 2006;20(9):988-997.

22. Higginbotham EJ, Alexis D. Is newer necessarily better? The evolution of incisional glaucoma surgery over the last 100 years. Am JOphthalmol. 2018;191:25-29.

23. World Glaucoma Association. Guidelines on Design and Reporting of Glaucoma Surgical Trials. Amsterdam, The Netherlands: The Hague; 2009.

24. Jayaram H, Strouthidis NG, Kamal DS. Trabeculectomy for normal tension glaucoma: outcomes using the Moorfields Safer Surgery technique. Br J Ophthalmol. Epub 2015 Jul 21.

25. Leske MC, Connell AM, Schachat AP, Hyman L. The Barbados Eye Study: prevalence of open angle glaucoma. Arch Ophthalmol. 1994;112(6):821-829.

26. Mason RP, Kosoko O, Wilson MR, et al. National survey of the prevalence and risk factors of glaucoma in St. Lucia, West Indies. Part I. Prevalence findings. Ophthalmology. 1989;96(9):1363-1368.

27. Leske MC, Wu SY, Honkanen R, et al; Barbados Eye Studies Group. Nine-year incidence of open-angle glaucoma in the Barbados Eye Studies. Ophthalmology. 2007;114(6):1058-1064. 
28. Leske MC, Wu SY, Nemesure B, Hennis A; Barbados Eye Studies Group. Causes of visual loss and their risk factors: an incidence summary from the Barbados Eye Studies. Rev Panam Salud Publica. 2010; 27(4):259-267.

29. Boodhna T, Crabb DP. Disease severity in newly diagnosed glaucoma patients with visual field loss: trends from more than a decade of data. Ophthalmic Physiol Opt. 2015;35(2):225-230.

30. Broadway D, Grierson I, Hitchings R. Racial differences in the results of glaucoma filtration surgery: are racial differences in the conjunctival cell profile important? Br J Ophthalmol. 1994;78(6):466-475.

31. Grant WM, Burke JF Jr. Why do some people go blind from glaucoma? Ophthalmology. 1982;89(9):991-998.

32. Merritt JC. Glaucoma blindness in African Americans: have 55 years of therapies, technologies, and talent altered blindness rates? $J$ Natl Med Assoc. 1996;88(12):809-819.

33. Racette L, Wilson MR, Zangwill LM, Weinreb RN, Sample PA. Primary open-angle glaucoma in blacks: a review. Surv Ophthalmol. 2003; 48(3):295-313.

34. Sommer A, Tielsch JM, Katz J, et al. Racial differences in the causespecific prevalence of blindness in east Baltimore. N Engl J Med. 1991; 325(20):1412-1417.

35. Tielsch JM, Sommer A, Katz J, Royall RM, Quigley HA, Javitt J. Racial variations in the prevalence of primary open-angle glaucoma: the Baltimore Eye Survey. JAMA. 1991;266(3):369-374.

36. Tham YC, Li X, Wong TY, Quigley HA, Aung T, Cheng CY. Global prevalence of glaucoma and projections of glaucoma burden through 2040: a systematic review and meta-analysis. Ophthalmology. 2014; 121(11):2081-2090.

37. Fansi AA, Papamatheakis DG, Harasymowycz PJ. Racial variability of glaucoma risk factors between African Caribbeans and Caucasians in a Canadian urban screening population. Can J Ophthalmol. 2009; 44(5):576-581.
38. Zangwill LM, Ayyagari R, Liebmann JM, et al; African Descent and Glaucoma Evaluation Study III Genomics Study Group. The African Descent and Glaucoma Evaluation Study (ADAGES) III: Contribution of genotype to glaucoma phenotype in African Americans: Study design and baseline data. Ophthalmology. Epub 2018 Jan 17.

39. Peters D, Bengtsson B, Heijl A. Factors associated with lifetime risk of open-angle glaucoma blindness. Acta Ophthalmol (Copenh). 2014; 92(5):421-425.

40. Peters D, Bengtsson B, Heijl A. Lifetime risk of blindness in open-angle glaucoma. Am J Ophthalmol. 2013;156(4):724-730.

41. Sommer A, Tielsch JM, Katz J, et al. Relationship between intraocular pressure and primary open angle glaucoma among white and black Americans. The Baltimore Eye Survey. Arch Ophthalmol. 1991;109(8): 1090-1095.

42. Rivera JL, Bell NP, Feldman RM. Risk factors for primary open angle glaucoma progression: what we know and what we need to know. Curr Opin Ophthalmol. 2008;19(2):102-106.

43. Heijl A. Glaucoma treatment: by the highest level of evidence. Lancet. 2015;385(9975):1264-1266.

44. Realini T. Selective laser trabeculoplasty for the management of open-angle glaucoma in St. Lucia. JAMA Ophthalmol. 2013;131(3): 321-327.

45. Ostermann J, Sloan FA, Herndon L, Lee PP. Racial differences in glaucoma care: the longitudinal pattern of care. Arch Ophthalmol. 2005; 123(12):1693-1698.

46. Mansouri K, Medeiros FA, Weinreb RN. Global rates of glaucoma surgery. Graefes Arch Clin Exp Ophthalmol. 2013;251(11):2609-2615.
Clinical Ophthalmology

\section{Publish your work in this journal}

Clinical Ophthalmology is an international, peer-reviewed journal covering all subspecialties within ophthalmology. Key topics include: Optometry; Visual science; Pharmacology and drug therapy in eye diseases; Basic Sciences; Primary and Secondary eye care; Patient Safety and Quality of Care Improvements. This journal is indexed on

\section{Dovepress}

PubMed Central and CAS, and is the official journal of The Society of Clinical Ophthalmology (SCO). The manuscript management system is completely online and includes a very quick and fair peer-review system, which is all easy to use. Visit http://www.dovepress.com/ testimonials.php to read real quotes from published authors. 